\title{
BT Anjiyografi ile Saptanan Arkus Aorta Tiplendirilmesi ve İskemik İnme ile Olan İlişkisi
}

\section{Aortic Arch Typing Diagnosed by CT Angiography and Its Relationship with Ischemic Stroke}

\author{
$\underline{\text { Hasan BAYINDIR }}^{1}{ }^{(\mathbb{D})}$, Sunay Sibel KARAYOL ${ }^{2}{ }^{(\mathbb{D})}$, Halil AY ${ }^{1}$ \\ 1 Harran Üniversitesi Tıp Fakültesi, Nöroloji Anabilim Dalı, Şanlıurfa, Türkiye \\ 2 Harran Üniversitesi Tıp Fakültesi, Radyoloji Anabilim Dalı, Şanlıurfa, Türkiye
}

Öz.

Amaç: Bir yıl içerisinde iskemik inme tanısı ile nöroloji kliniğine başvuran 379 hastanın, radyolojik görüntülerini retrospektif olarak inceleyerek arkus aorta tiplerinin ve varyasyonlarının belirlenmesi, aorta tiplerinin sıklığının tespiti ve iskemik inmenin lokalizasyonu ile olan ilişkilerini araştırmaktır.

Materyal ve metod: Şubat 2017-2018 tarihleri arasında nöroloji kliniğine iskemik inme tanısı ile başvuran 379 hasta retrospektif olarak değerlendirildi. Beyin manyetik rezonans görüntüleri (MRG), beyin bilgisayarlı tomografi (BT) ve karotis vertebral BT anjiografileri incelendi. Arkus aorta tipleri, varyasyonları, sıklığı, iskemik inmenin lokalizasyonu ile olan ilişkileri belirlendi.

Bulgular: İskemik inme ile takip edilen ve karotis vertebral BT angiografi çekilen toplam 379 hastanın 219'u (\%57.8) erkek, 160' । (\%42.2) kadın hastaydı. 288 hastada Tip1, 80 hastada Tip2 ve 11 hastada Tip3 arkus aorta mevcuttu. Çalışmaya katılan hastalardan 220'si ön sistem kaynaklı enfarkta, 159'u ise arka sistem kaynaklı enfarkta sahipti. Ön sistem enfaktı en çok \%73,8 olarak Tip2 hastalarında vardı. Ön-arka ve sağ-sol dolaşım ayrımına göre yapılan değerlendirmede Tip1 arkuslu hastanın \%30,9'unda, Tip2 arkuslu hastanın \%61,2'sinde, Tip3 arkuslu hastanın \%63,6'ünde sol-ön sistem kaynaklı enfarkt tespit edildi.

Sonuç: Tüm iskemik inmelerde ön sistem sirkülasyonu kaynaklı enfarktlar daha sıktır. Arkus aorta tiplendirmesinde ise en sık Tip1 tespit edilmiştir. Ön sistem kaynakıı infaktların en sık Tip2 arkus aortada ve sol taraflı olduğu, arka sistem kaynaklı enfarktların ise daha sık Tip1 arkus aortalı hastalarda olduğu ve bu enfarktların da sağ arka sistem dolaşımda daha belirgin olarak izlendiği göze çarpmıştır.

Anahtar Kelimeler: Aortik ark, Aort tipleri, Arkus varyasyonları, İskemik inme

Abstract

Background: The radiological images of 379 patients with a diagnosis of ischemic stroke who were admitted to neurology department in one year are retrospectively analyzed, to determine the types and variations of the aortic arch, frequency and its relationship with localization of ischemic stroke.

Materials and Methods: Retrospectively examined, the brain magnetic resonance imaging (MRI), brain computed tomography (CT) and carotid vertebral CT angiographies of 379 patients who were admitted to neurology department between february 2017 and 2018 were diagnosed with ischemic stroke. Arcus aorta types, variations, frequency and their relationship with localization of ischemic stroke were determined.

Results: 219 (57.8\%) of the 379 cases were male and 160 (42.2\%) were female patients with ischemic stroke diagnosed by carotid vertebral CT angiography. 288 patients had Type 1, 80 patients had Type 2, and 11 patients had Type 3 archus aorta. 220 of all patients had infarction originating from the anterior system and 159 had infarction originating from the posterior system. There was also type 2 cases with an anterior system rate of $73.8 \%$. In the evaluation made according to the anterior-posterior and left-right circulation distinction, left-anterior infarct originated from $30.9 \%$ of the Type 1 archus case, $61.2 \%$ of the Type 2 case, and $63.6 \%$ of the Type 3 case were detected.

Conclusion: Infarcts arising from anterior system circulation are more common in all ischemic strokes. Type 1 was the most common in the archus aorta typing. It was observed that the anterior system originated infarcts were the most common in the Type 2 archus aorta and left-sided, and the infarcts from the posterior system were more frequent in the cases with Type 1 archus aorta, and these infarcts were observed more clearly in the right posterior circulation.

Key words: Aortic arch, types of aorta, arcus variations, ischemic stroke.

Sorumlu Yazar I

Corresponding Author

Dr. Öğr Üyesi Hasan Bayındır

Harran Üniversitesi Tıp fakültesi

Nöroloji Anabilim Dalı

Osmanbey Kampüsü

Haliliye/Şanlıurfa, Türkiye.

Tel: 05054309147

e-mail: h.bayindir@hotmail.com

Geliş tarihi / Received:

17.07.2020

Kabul tarihi / Accepted:

20.10.2020

DOI: $10.35440 /$ hutfd. 769032

8. Ulusal Beyin Damar Hastalıkları Kongresi. 3-6 Mayıs 2018, Sheraton Çeşme Otel, İzmir'de P-026 numaralı e poster olarak sunulmuştur. 


\section{Giriş}

Akut iskemik inme, beyni besleyen arteriyel damarlardan birinde ani olarak gelişen tıkanıkığa bağlı olarak beyin dokusunda iskemi gelişmesine bağlı, beyin fonksiyonlarının yitirimesi ve buna bağlı olarak fokal nörolojik defisitlerle seyreden ciddi hayati tehlike oluşturan bir hastalık grubudur. İnme etyolojisinde aterosklerotik tromboemboliler başlıca nedenlerdendir. Çoğunlukla kötü prognozlu seyreden serebral hemisfer enfarktları internal karotis arter veya proximal middle serebral arter (MCA) tıkanıkığına bağlı oluşur. İskemik inmede etyoloji, inmenin prognozunu, tedavi ve takip şeklini belirleyici bir faktördür (1). Akut iskemik inmenin başlıca tedavi prensibi kan akımının yeterli düzeyde tekrar sağlanması ve tıkanıklık bölgesindeki hipoperfüzyonun düzeltilmesidir (2).

Aortik ark'ın konjenital anomalilerinin, geleneksel olarak ilk sınıflandırması 1964 yılında James Stewart ve ark'ları tarafından tanımlanmıştır (3). Günümüzde tanısal görüntüleme metodlarında ortaya çıkan yeni gelişmelere bağlı olarak, vasküler yapıların anatomisi daha iyi anlaşılmış ve yeni tiplendirmeler yapılmıştır.

Arkus aorta üst extremite ve beyni besleyen vasküler yapıların orjinini oluşturur. Yaklaşık olarak sekiz tip farklı arkus aorta tipi tanımlanmıştır. Bunlardan çoğunlukla ilk üç tip daha sıklıkla görülmektedir (4). Bu çalışmamızda 20172018 şubat ayları arasındaki bir yıllık dönem içinde hastanemiz nöroloji kliniğine iskemik inme tanısı ile başvuran ayaktan ya da yatarak tedavi gören 379 hastanın, çekilen beyin manyetik rezonans (MR) görüntüleri, beyin bilgisayarlı tomografi (BT) ve karotis vertebral BT anjiografileri retrospektif olarak incelenerek arkus aorta tiplerinin belirlenmesi, varyasyonları, arkus aorta tiplerinin sıklığının tespiti ve iskemik inme lokalizasyonu ile olan ilişkileri incelendi.

\section{Materyal ve Metod}

Çalışma için 07.06.2018 tarih 06 nolu oturum ve 28 nolu kararı ile Harran Üniversitesi Tıp Fakültesi Etik Kurulu'ndan onay alındı. 2017-2018 şubat aylarını kapsayan bir yıl içerisinde nöroloji kliniğine iskemik inme tanısı ile başvuran, ayaktan veya yatarak tedavi edilen 379 hasta retrospektif olarak incelenmek üzere çalışmaya alındı. Dışlama kriterimiz yoktu. Hastaların ayrıntılı dosyaları incelendi. Radyolojik görüntüleri, hastane bilgi işlem sisteminde kullanılan PACS görüntüleme sistemi üzerinden değerlendirildi. Hastalar yaş, cinsiyet ve inmenin gerçekleştiği mevsim olarak kayıt altına alındı. Klinik ve radyolojik olarak iskemik inme tanısı alan hastaların beyin görüntüleri, lokalizasyon açısından çalışmaya katılan, radyoloji anabilim dalı tarafından değerlendirilerek sınıflandırıldı. Hastalara 1.5 Tesla Siemens Magnetom Symphony MR cihazı ile beyin MR ve diffüzyon MR çekilmiş̧i. Anterior serebral arter (ACA) ve middle serebral arter (MCA)'in beslediği frontal lob, parietal lob ve temporal lobtaki enfaktlar ön sistem (anterior) enfarktı olarak isimlendirildi. Oksipital lob, serebellum ve beyin sapında görülen enfarktlar arka sistem (posterior) enfarktı olarak kayıt altına alındı. Ayrıca vasküler orjine göre değerlendirme olarak, sağ karotis arter ve sol karotis arter kaynaklı olarak gelişen iskemik inme lezyonları ön sistem (anterior sirkülasyon) enfarktı, her iki vertebral arter kaynaklı iskemik inmeler ise arka sistem (posterior sirkülasyon) enfarktı olarak tanımlandı. Çalışmaya alınan hastaların karotis vertebral BT anjiografileri GE 256 slice dual CT cihazı ile çekilmişti ve üç boyutlu rekonstrüksiyon yapılarak değerlendirildi. Arkus aortadan çıkan ana damarların çıkış sırası ve şekli göz önüne alınarak sınıflandırma yapıldı. Bu sınıflandırmada, aortik ark anomalileri ve varyasyonları Natsis ve arkadaşlarının çalışmalarında belirttikleri 8 tip olarak tanımladıkları sınıflandırma parametreleri kullanılarak yapıldı (4).

\section{Bulgular}

Karotis vertebral BT anjiografi çekilen toplam 379 hastanın 219 'u (\%57.8) erkek, 160'ı (\%42.2) kadın hastaydı. Çalışmaya katılan hastaların yaş ortalaması $61.8 \pm 13.4$ idi. Erkeklerin yaş ortalaması $62.7 \pm 13.1$, kadınların yaş ortalaması $60.5 \pm 13.8$ olarak bulundu.

288 hastada (\%76) Tip1, 80 hastada (\%21.1) Tip2 ve 11 hastada (\%2.9) Tip3 arkus aorta mevcuttu. Çalışma popülasyonumuzda belirtilen 8 tip ile yapılan sınıflamada, ilk üç tip tespit edildi, geri kalan tiplere rastlanılmadı (Şekil 1).

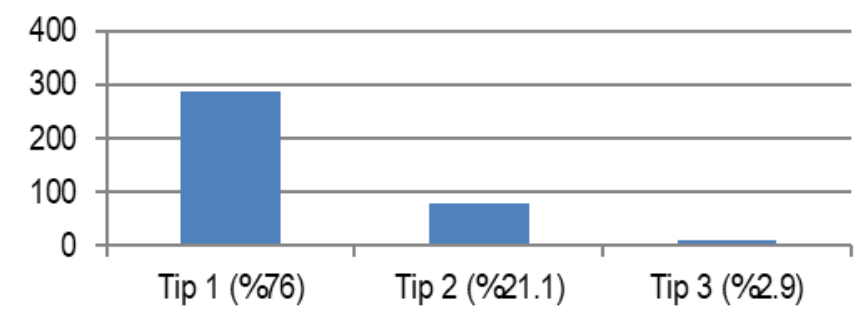

Şekil 1. Arkus aorta tipleri

Çalışmaya alınan 379 hastadan 220'si (\%58) ön sistem kaynaklı enfarkta, 159'u ise (\%42) arka sistem kaynaklı enfarkta sahipti. Tip 1 Arkus aortası olan hastaların 154'ünde (\%53.5), Tip2 arkuslu hastaların 59'unda (\%73.8), Tip3 arkuslu hastaların 7'sinde (\%63.6), ön sistem enfarktı vardı. Arka sistem sirkülasyon kaynaklı enfarktlar da kendi içinde değerlendirildi. Tip1 arkuslu hastaların 134'ünde (\%46.5), Tip2 arkuslu hastaların 21 'inde (\%26.8), Tip3 arkuslu hastaların ise 4'ünde (\%36.4) arka sistem enfarktı mevcuttu (Tablo 1).

Toplam 379 hastanın 219'unda (\%57.8) sol taraflı enfakt alanı vardı. Aortik ark tiplendirmesinde tespit edilen, 288 Tip1 arkuslu hastanın 149'unda (\%51.7), 80 Tip2 hastanın 59'unda (\%73.8), 11 Tip3 arkuslu hastanın tamamında (\%100) sol sirkülasyon enfarktı vardı (Tablo 2). 
Ön-arka ve sağ-sol sirkülasyon ayrımına göre yapılan değerlendirmede 288 Tip1 arkuslu hastanın 89'unda (\%30.9), 80 Tip2 arkuslu hastanın 49'unda (\%61.2), 11 Tip3 arkuslu hastanın 7'sinde (\%63.6) sol ön sirkülasyon kaynaklı enfarkt tespit edildi. Ayrıca 75 Tip1 (\%26) ve 11 Tip2 (\%13.8) arkuslu hastada da sağ arka sirkülasyon enfarktı vardı (Tablo 3).

Tablo 1. Ön-arka dolaşım enfarktı dağılımı

\begin{tabular}{|l|c|c|c|}
\hline \multirow{2}{*}{ Tip 1 } & Anterior & Posterior & Toplam \\
\hline \multirow{2}{*}{ Tip 2 } & 154 & 134 & 288 \\
\cline { 2 - 4 } & $\% 53.5$ & $\% 46.5$ & \\
\hline \multirow{2}{*}{ Tip 3 } & 59 & 21 & 80 \\
\cline { 2 - 4 } & $\% 73.8$ & $\% 26.2$ & \\
\hline \multirow{2}{*}{ Toplam } & 7 & 4 & 11 \\
\cline { 2 - 4 } & $\% 63.6$ & $\% 36.4$ & 379 \\
\cline { 2 - 4 } & 220 & 159 & \\
\hline
\end{tabular}

Tablo 2. Sağ-sol taraflı dolaşım enfarktı dağıımı

\begin{tabular}{|l|c|c|c|}
\hline & Sağ & Sol & Toplam \\
\hline \multirow{2}{*}{ Tip 1 } & 139 & 149 & 288 \\
\cline { 2 - 4 } & $\% 48.3$ & $\% 51.7$ & \\
\hline \multirow{2}{*}{ Tip 2 } & 21 & 59 & 80 \\
\cline { 2 - 4 } & $\% 26.2$ & $\% 73.8$ & \\
\hline \multirow{2}{*}{ Tip 3 } & - & 11 & 11 \\
\cline { 2 - 4 } & - & $\% 100$ & \\
\hline \multirow{2}{*}{ Toplam } & 160 & 219 & 379 \\
\cline { 2 - 5 } & $\% 42.2$ & $\% 57.8$ & \\
\hline
\end{tabular}

Tablo 3. Sağ- sol ve ön-arka dolaşım enfarkt sıklğının ayrı ayrı değerlendirilmesi

\begin{tabular}{|c|c|c|c|c|c|}
\hline & Sağ anterior & Sol anterior & Sağ posterior & Sol posterior & Toplam \\
\hline \multirow{2}{*}{ Tip 1 } & 64 & 89 & 75 & 60 & 288 \\
\cline { 2 - 6 } & $\% 22.2$ & $\% 30.9$ & $\% 26$ & $\% 20.8$ & $\% 76$ \\
\hline \multirow{2}{*}{ Tip 2 } & 10 & 49 & 11 & 10 & 80 \\
\cline { 2 - 6 } & $\% 12.5$ & $\% 61.2$ & $\% 13.8$ & $\% 12.5$ & $\% 21.1$ \\
\hline \multirow{2}{*}{ Tip 3 } & - & 7 & - & 4 & 11 \\
\cline { 2 - 6 } & & $\% 63.6$ & & $\% 36.4$ & $\% 2.9$ \\
\hline \multirow{2}{*}{ Toplam } & 74 & 145 & 86 & 74 & 379 \\
\cline { 2 - 6 } & $\% 19.5$ & $\% 38.3$ & $\% 22.7$ & $\% 19.5$ & \\
\hline
\end{tabular}

379 hastanın alındığı çalışmamızda, arkus aorta tiplendirmesinde aortadan 8 dallanma tipinden en çok Tip1 (\%76), sonrasında sırasıyla Tip2 (\%21.1) ve Tip3 (\%2.9) arkus aorta tespit edildi (Şekil 2).

Tüm iskemik inmelerde ön sistem sirkülasyon kaynaklı enfarktların daha sık olduğu görüldü. Arkus aorta tiplendirmesinde ön sistem sirkülasyon kaynaklı enfaktların en sık Tip2 arkus aortada olduğu görüldü. Ayrıca arkus aorta tiplendirmesinde arka sistem sirkülasyon kaynaklı enfarktların ise daha sık Tip1 arkus aortada olduğu ve bu enfarktların da sağ arka sistem sirkülasyonda daha belirgin olarak izlendiği görüldü.

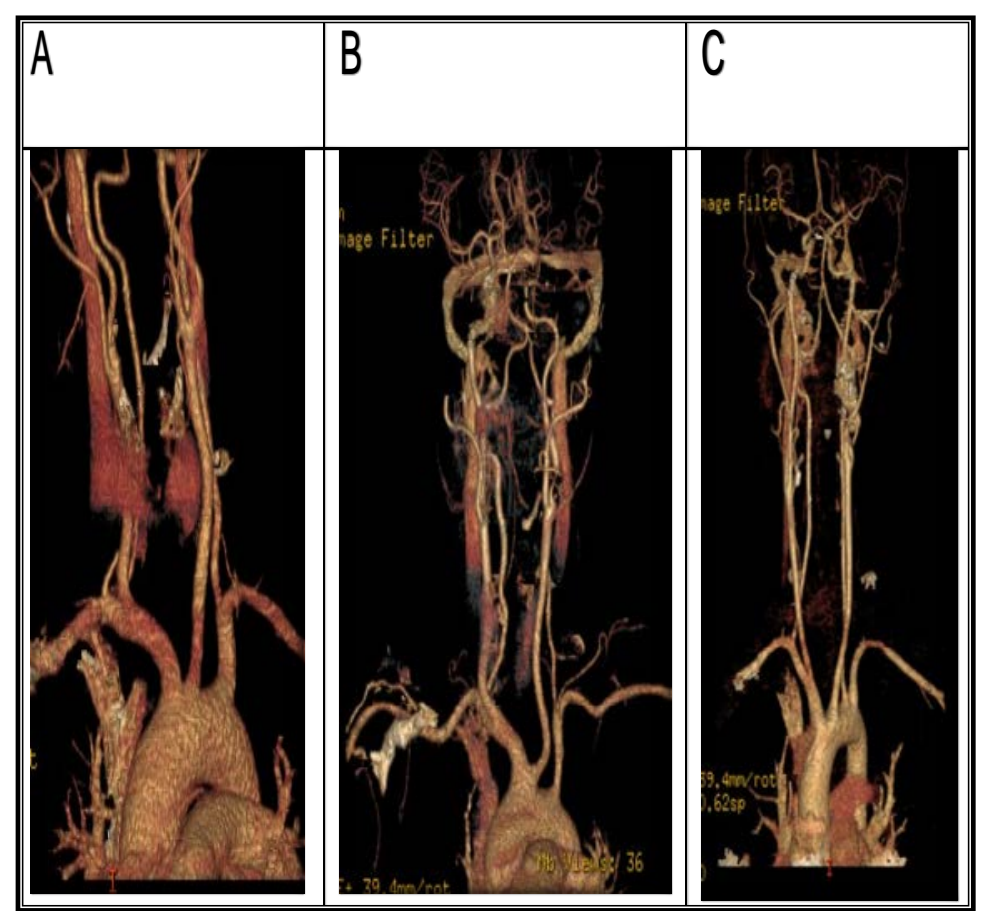

Şekil 2. Arkus aorta görüntüleri

A: Tip1 arcus aorta,

B: Tip2 (bovine ark) arkus aorta,

C : Tip3 arkus aorta .

Kaynak: Kendi çalışma hastalarımızdan

Şekil 3. Arkus aorta tipleri

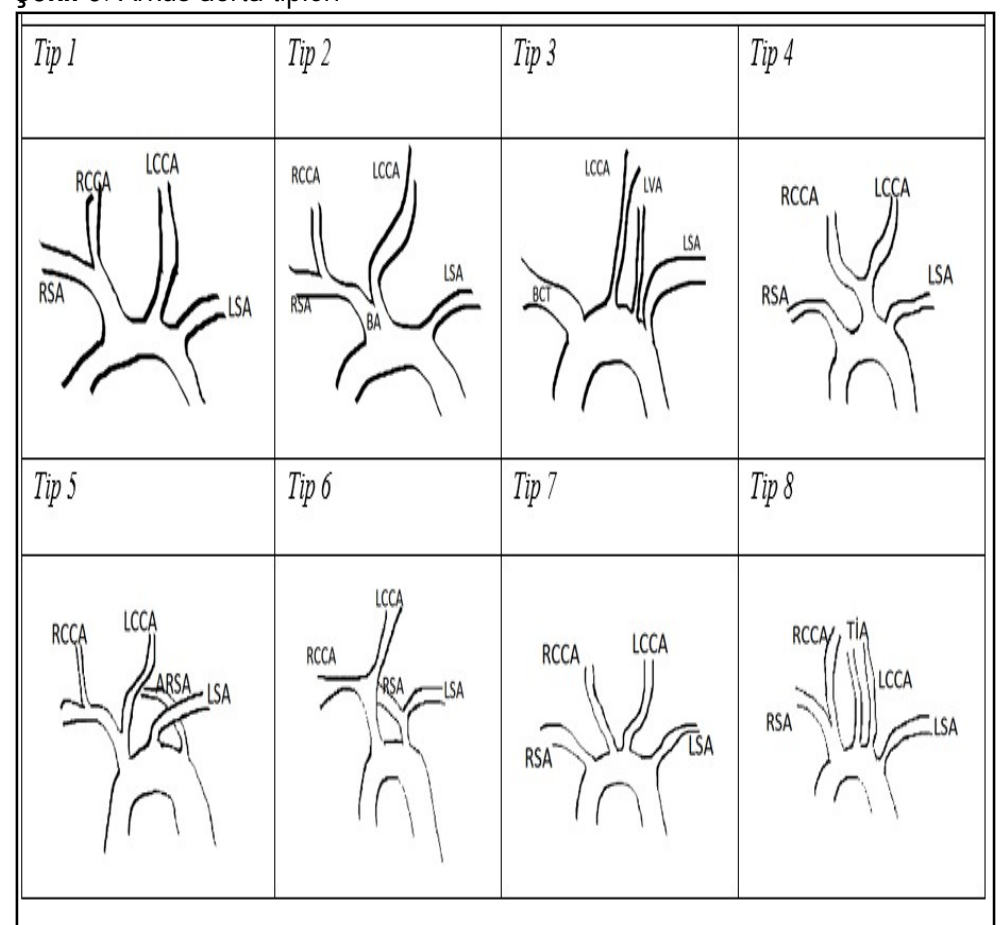

AA: Arkus aorta, BCT: Brakiyosefalik arter,

LCCA: Sol karotis komunis arter, LSA: Sol subklaviyen arter,

RCCA: Sağ karotis komunis, RSA: Sağ subklaviyen arter, BA: Bovine ark, LVA: Sol vertebral arter, ARSA: Aberran sağ subklaviyen arter,

TiA: Tiroid ima arter.

KAYNAK : Rojas M ve ark.(7)'dan esinlenerek kendi çizimlerimizdir. 


\section{Tartışma}

İskemik inmelerin etyolojik nedenleri arasında arkus aorta tiplerinin bir etken olduğu ve toplum içinde ne kadar sıklıkta görüldüğü tartışılmıştır. Arkus aorta tipleri ile iskemik inmenin yerleştiği serebral lokalizasyon arasındaki ilişki araştırılmıştır.

Fetal gelişim sırasında, embriyolojik olarak trunkus arterizosus ve aort kesesinden altı dal çıkar (5). Fetal gelişimin farklı evrelerinde bazı dallar kaybolur ve beşinci dalın gelişimi tamamen oluşmaz. Her iki taraftaki aort dallarının kaybı başlıca ana vasküler yapıların oluşumunu bozar. Aortik ark sol dördüncü dal tarafından oluşturulur. Sağ subklaviyen arter, sağ dördüncü aortik ark, sağ dorsal aorta ve sağ yedinci inter segmental arterden kaynaklanır. Sağ komun karotis arter (CCA), sağ üçüncü aortik ark ve sol CCA da sol üçüncü aortik arktan oluşur. Sol subkalviyen arter sol yedinci inter segmental arterden kaynaklanır. Sol vertebral arter altıncı inter segmental arter kısımlarından oluşur. Embriyonik gelişimdeki herhangi bir aksaklık veya değişiklik aortik ark varyasyonlarına neden olur (6). Arkus aorta tiplendirmeleri 1'den 8'e kadar numaralandırllan tiplerden oluşur. Literatürde benzer şekilde bizim çalışmamızda da sıkıklıkla görülen tiplerden olan Tip1, Tip2 ve Tip3 arkus aorta tespit edilmiştir. Bunlardan daha sıkıkla karşılaşılan Tip1 arkus aorta, normal tip olarak adlandırımış, diğer tiplendirmeler ise varyasyon olarak değerlendirilmiştir. Tip1 arkus aortanın görülme sıklı̆ı \%71-83 oranındadır. Benzer olarak bizim çalışmamızda da \%76 olarak bulunmuştur.

Tip1 arkus aortadan sırasıyla brakiyosefalik trunkus, sol karotis komunis arter ve sol subklaviyen arter çıkar. Tip2 arkus aorta ya da genel adlandırması ile 'bovine ark' aorta, brakiyosefalik trunkus ve sol karotis komunis arter birlikte arkus aortadan ortak bir dal ile, yan tarafindan da sol subklaviyen arter tek başına çıkar. Literatürde Tip2 yani, bovine ark aortanın sıklığı \%15-21 olarak tanımlanmıştır. Tip2 arkus aorta ikinci sıklıkta görülen arkus aorta varyasyonudur. Bizim çalışmamızda da bu oranlara benzer olarak \%21.1 sıklıkta tespit edilmiştir. Tip3 arkus aortada da sırasıyla, sağ brakiyosefalik trunkus, sol karotis komunis arter, sol vertebral arter doğrudan ve sol subklaviyen arter arkus aortadan çıkar. Tip3 arkus aorta \%0.16-8.2 oranında görülür. Bizim çalışmamızda Tip3 arkus aorta \% 2.9 oranında görülmüştür. Tip4 arkus aorta \%0.8-23 gibi geniş bir aralıkta farklı oranlarda görülebilir. Tip4 arkus aortada brakiyosefalik trunkus yoktur. Sağ subklaviyen arter ve sol subklaviyen arter doğrudan arkus aortadan çıkarken, her iki karotis komunis ortak tek bir dal ile çıkar. Tip5 arkus aortada sırasıyla, her iki karotis komunis ortak tek bir dal ile çıkarken, sol subklaviyen arter ve aberran sağ subklaviyen arter ayrı olarak çıkar. Aberran sağ subklaviyen arter soldan çıkıp sağa doğru dönerek ilerler. Tip6 arkus aortada Tip5 arkus aortaya benzer şekilde her iki karotis arter ortak tek bir dal ile, farklı olarak her iki subklaviyen arter de orta tek dal olarak, yani arkus aortadan iki trunkus halinde çıkar. Tip7 arkus aortada sırasıyla sağ subklaviyen arter, sağ karotis komunis, sol karotis komunis ve sol subklaviyen arter ayrı ayrı çıkar. Tip8 arkus aortadan da brakiyosefalik trunkus, tiroid ima arter, sol karotis komunis ve sol subklaviyen arter çıkar $(4,7)$ (Şekil 3).

Bizim çalışmamızda da literatüre benzer şekilde en sık görülen ilk üç tip olan Tip1, Tip2 ve Tip3 arkus aorta görülmüştür. Bunlar içinde en sık olarak \%76 oranında Tip1 arkus aorta bulunmuştur. Geriye kalan Tip4, Tip5, Tip6, Tip7 ve Tip8 arkus aorta tespit edilmemiştir.

Bovine ark aorta, sol CCA'nın brakiyosefalik arter ile ortak bir gövdeden ortaya çıktığı durumda tanımlanır (8). Almanya'da 2019 ylında Tip2 bovine ark aortalı hastalarda yapılan çalışmada kontrol grubu ile kaşılaştırma yapılmış ve aortada, bovine arka bağlı oluşan kan akımı akış özelliği değişikliğine bağlı olarak, \%25.7 görülme sıkığı ile Tip2 bovine arklı hastalarda daha sık iskemik inme görüldüğü bildirilmiştir (9). Bovine ark aortalı kişilerde aort disseksiyonu da benzer şekilde daha sıkça görülmekte ve buna bağı iskemik inme sıklığında artış olmaktadır (10).

Bizim çalışmamızda da arkus aorta tiplerinin iskemik inme ile olan birlikteliği araştırıımış. En çok ön sistem sirkülasyonlu enfarktlar tespit edilmiş. Tip2 arkuslu olguların \%73.8'inde, Tip3 olguların \%63.6'sında ve Tip1 olguların \%53.5'inde ön sistem sirkülasyonlu enfarktlar görülmüştür. Tipler arasında yapılan değerlendirmede anatomik özelliklere bağlı olarak literatüre benzer, Tip2 bovine ark'lı arkus aortalı olgularda, iskemik inmenin daha belirgin olarak ön sistem sirkülasyona bağıl olarak geliştiği görülmüştür.

Yine anatomik yapılara bağı olarak Tip3 arkus aortalı olguların tamamı sol karotis komunis ve sol vertebral arter kaynaklı iskemik inmeye neden olduğu görülmüştür. Illgi çekici olarak Tip3 arkus aortalı olgularda hiç sağ taraflı enfarkt tespit edilmemiştir.

Her iki karotis komunis arter (anterior sirkülasyon) ve her iki vertebral arter (posterior sirkülasyon) tek tek değerlendirildiğinde, Tip2 arkus aortalı olgularda \%61.2 oranında sol anterior (sol karotis komunis) sirkülasyonlu enfarkt olduğu tespit edilmiştir.

Posterior sirkülasyonlu enfarktlar da taraf ayrımı açısından değerlendirilmiş ve sağ posterior sirkülasyon (\%22.7) enfarkt oranları, sola göre (\%19.5) daha yüksek oranda bulunmuştur.

Anterior sirkülasyon enfarktları tüm olgular içinde değerlendirilmiş sol anterior \%38.3 oranında, sağ anterior \%19.5 oranında bulunmuş. Sol anterior sirkülasyonlu enfarktların daha çok olduğu görülmüştür.

Tüm bu anatomik sınıflandırma ve iskemik inme lokalizasyonları birlikte değerlendirildiğinde, vasküler yapıların arkus aortadan çıkış sırası ve şekli göz önünde bulundurularak, vasküler yatak içindeki kan akım hızının, damar duvar yapısı içinde plak oluşumuna, etkili olduğu düşünülür. 
Çalışmamızın kısıtııı̆̆ı, retrospektif bir çalışma olması ve bu nedenle vasküler yapılardaki akım basınclarının ölçülememesidir. Bu çalışma, arkus aorta varyasyonlarının iskemik inmede etyolojik faktör olarak değerlendirmesini incelemek isteyen ileriki çalışmalara fikir vermesi açısından paylaşılmıştır.

Etik onam: Çalışma için 07.06.2018 tarih 06 nolu oturum ve 28 nolu kararı ile Harran Üniversitesi Tıp Fakültesi Etik Kurulu'ndan onay alındı.

\section{Kaynaklar}

1. Adams HP, Bendixen BH, Kappelle LJ, Biller J, Love BB, Gordon DL et al. Classification of subtype of acute ischemic stroke definitions for use in a multicenter clinical trial. TOAST. Trial of Org 10172 in Acute Stroke Treatment. Stroke. 1993;24(1):35-41.

2. Prabhakaran S, Ruff I, Bernstein R. Acute Stroke Intervention A Systematic Review. JAMA. 2015;313(14):1451-62

3. Li S, Wena H, Liang M, Luoa D, Qin Y, Liao Y et al. Congenital abnormalities of the aortic arch: revisiting the 1964 Stewart classification. Cardiovascular Pathology. 2019;39:38-50.

4. Natsis K, Tsitouridis I, Didagelos M, Fillipidis A, Vlassis K, Tsikaras P. Anatomical variations in the branches of the human aortic arch in 633 anigoraphies: clinical significance and literature review. Surg Radiol Anat. 2009;31(5):319-23.

5. Kellenberger CJ. Aortic arch malformations. Pediatr Radiol. 2010;40:876-84.

6. Kondori BJ, Asadi MH, Rahimian E, Tahsini MR. Anatomical Variations in Aortic Arch Branching Pattern. Arch Iran Med. 2016;19(1):72-74 7. Rojas M, Muete W, Quijano Y. Anatomical variations of the aortic arch in a sample of Colombian population. Rev. Fav. Med. 2017;65(1):49-54. 8. Han J, Xiang H, Ridley WE, Ridley LJ. Bovine aortic arch. Journal of medical imaging and radiation oncology. 2018;62(1):20-21.

9. Syperek A, Angermaier A, Kromrey ML, Hosten N, Kirsch M. The socalled "bovine aortic arch": a possible biomarker for embolic strokes? Neuroradiology. 2019;61(10):1165-72.

10. Dumfarth J, Peterss S, Kofler M, Plaikner M, Ziganshin BA, Schachner T et al. In DeBakey Type I Aortic Dissection, Bovine Aortic Arch Is Associated With Arch Tears and Stroke. The annals of thoracic surgery. 2017;104(6):2001-08. 